\title{
Educational development partnerships and practices \\ Helping librarians move beyond the one-shot
}

\section{G} iven the current, widespread concern about "fake news" and information disorder, those working in post-secondary contexts have recognized a pressing need to develop students' digital literacy (DL). Based on our experience collaboratively designing and delivering a faculty workshop on "Teaching Students about Fake News," we see library connections to educational development as one way to address this need. Because faculty members design, develop, and deliver the requisite curriculum-and are often called upon to address the challenges that their students face in navigating, evaluating, and applying online contentthey are frequently a first point of contact for help. ${ }^{1}$ Research examining student interactions with online news, social media, and other digital content also demonstrates how faculty play a vital part in facilitating and supporting critical digital engagement. ${ }^{2}$ All of this underscores the importance of faculty roles in promoting digital and information literacies. A fruitful strategy for librarians to build better connections with faculty is through educational development strategies.

While educational strategies stemming from instructional design have received some attention in library research and practice, there has been much less discussion about potential library connections to educational development. Educational development (ED) is a term commonly used to describe the intentional planned actions and activitiesoften professional development opportuni- ties, instructional programs, or other educational initiatives - that faculty members and institutions undertake to enhance teaching and learning in higher education. ${ }^{3}$ The role of educational developers, many of whom work as pedagogical experts within teaching centers, is to facilitate individual faculty learning, as well as wider instructional and organizational development, with the goal of "helping colleges and universities to function effectively as teaching and learning communities." Recent discussion about connections between libraries and ED highlights a number of ways that the library community can join broader conversations about teaching and learning in higher education, particularly through wider collaborations with centers for teaching and greater involvement in educational development. ${ }^{5}$

As colleagues who are collocated within our university's Library and Learning Centre, we recognized an opportunity to foster digital literacy through educational development practices. Since the "fake news" phenomenon was of great interest on our campus, we looked to promote digital literacy by creating a faculty workshop on disinformation within an established and well-recognized program

Sara Sharun is assistant professor and librarian, email: ssharun@mtroyal.ca, Erika E. Smith is assistant professor and faculty development consultant, email: eesmith@ mtroyal.ca, at Mount Royal University

(c) 2020 Sara Sharun and Erika E. Smith 
within the Academic Development Centre. Integrating approaches from the fields of educational development and library and information science (LIS) to engage with these topical issues enabled us to build individual and institutional awareness of digital literacy and extend the reach of instructional support on campus.

This article provides an example of how librarians can leverage educational development strategies to move beyond one-shot instruction by engaging faculty both as learners and as educators, and how partnering with educational developers can help disperse information and digital literacies across the university curriculum.

\section{An educational development initiative aimed at fake news}

As it is on many campuses these days, fake news has been a hot topic at our institution. Library-led interventions to teach students about fake news are common, as evidenced in the number of online teaching resources, conference presentations, and publications appearing among the LIS community over the past few years. However, while the discourse around fake news in academic libraries is often centered on students, there are far fewer examples of including faculty in outreach and instruction efforts addressing information disorder and disinformation.

In our roles as a liaison librarian to the School of Communication Studies and an educational developer, who provides expertise in emerging technologies, we noticed that both educators and students were overwhelmed by-and, in many cases, ill-equipped to deal with-fake news. While some of these issues were being covered through existing library instruction with our undergraduate students, formal initiatives helping educators to discern disinformation and build their own capacities with digital literacies did not exist. As a result, we saw faculty learning and development as an urgent area to address. We collaborated to create a new workshop that allowed us to gauge and respond to faculty needs while also opening up space for discussions about information and digital literacies more broadly.

In our 90-minute educational development workshop, "Teaching Students about Fake News: Curriculum Strategies for Navigating Bias and False Content Online," we illustrated ways for faculty to foster students' critical assessment of digital information and scaffold digital literacies within their own curriculum. The workshop format allowed educators to build their own knowledge and skills in these areas in a supportive environment. We successfully cofacilitated the workshop three times in the spring and fall of 2019. Voluntary registration was available to faculty and staff across campus, and the workshop audience included faculty from a variety of disciplines, as well as librarians and university staff who provide support services for students.

Our workshop begins with an activity that enables us as facilitators to check for common (mis)conceptions and identify shared areas of concern that we can respond to either in the session or in separate one-toone consultations. We follow this discussion with definitions and examples of misinformation, disinformation, and malinformation drawn from contemporary media and from the literature.

After establishing foundational terminology and a shared understanding of common issues connected to current examples, we then transition to a brief hands-on activity, where participants evaluate two similar online health sources. Using research from the Stanford History Education Group ${ }^{6}$ and short explanatory videos by Mike Caufield, ${ }^{7}$ we then work with the group to hone concrete strategies (including lateral reading) that are efficient and effective in helping to determine the credibility of such sources. Several faculty members have told us that they found this particular activity to be so helpful that they planned to use it with their own students. We conclude the workshop by providing a model for building digital literacies and presenting assessment ideas and resources that educators can use in their lives and in the classroom. 
Recent research shows that digital literacy conversations do not typically take place in university classrooms, ${ }^{8}$ and while our initial interactions with workshop participants reflected these findings, we are hopeful that collaborative initiatives like ours could help to close this gap. Faculty in our workshops generally indicated that although they were concerned with students' exposure to information disorder, they had not incorporated these concepts into their assignments and were more accustomed to steering students towards academic sources and discouraging the use of "popular" sources than they were to helping students tackle source evaluation. By building relationships, illustrating pragmatic strategies, and making space for critical conversations, we

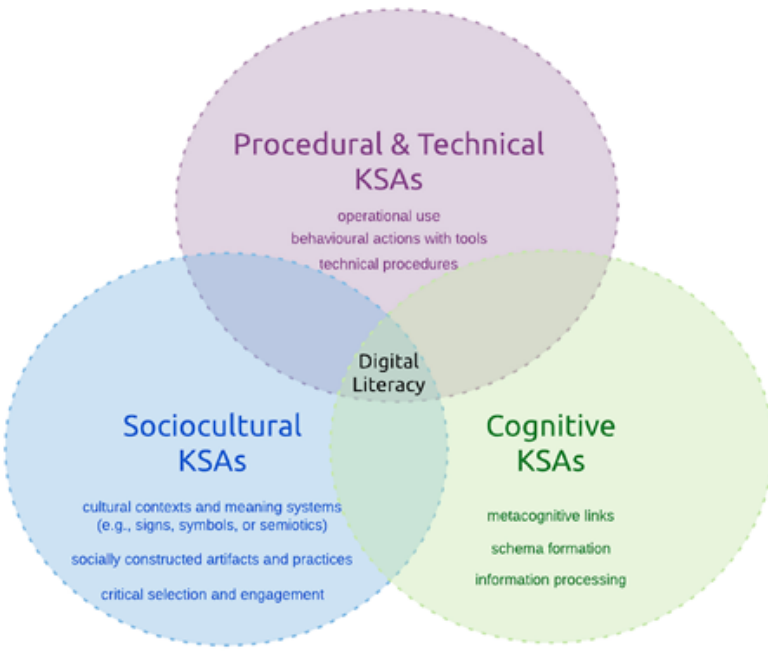

Diagram illustrating three interconnected domains of digital literacy involving procedural and technical, cognitive, and sociocultural knowledge, skills, and attributes. Erika E. Smith, Renate Kahlke and Terry Judd, 2018, https://doi.org/10.6084 /m9.figshare.11908425.

\section{are optimistic}

that this pattern could change in the future. We were especially encouraged that a number of participants followed up with us individually for further curriculum consultation as they worked to incorporate strategies for combating fake news into their own teaching.

\section{Key takeaways}

While the disciplinary context of particular digital literacies is certainly important, it is equally clear that concerns about students' ability to effectively use technologies to create, find, evaluate, and communicate online information span and transcend the disciplines. In our educational development workshop, we therefore highlighted a transdisciplinary model for developing digital literacy $^{9}$ to demonstrate how DL knowledge, skills, and attributes (KSAs) could be incorporated into any disciplinary context or level of study.

Using educational development approaches to discuss digital literacy as a curricular issue had a number of benefits. We were able to reinforce the importance of faculty roles in developing digital literacies by showing recent evidence that students seek their guidance on source selection, evaluation, and use. This created opportunities for discussion about the impact on students when faculty exclusively require scholarly sources, a practice that inhibits development and transfer of information evaluation skills between the classroom and everyday life. ${ }^{10}$

Often, the relevance or meaning of information and digital literacies can be difficult to communicate effectively with faculty immersed in their disciplines who may feel they have little time or lack an ability to address such topics. In our workshop, we encouraged faculty to see how information and digital literacies could be incorporated into their curriculum in meaningful ways and to challenge their assumptions that these KSAs are beyond the scope of their course content or disciplinary expertise.

In particular, we prompted faculty to consider the limitations of some of their traditional academic approaches to information 
seeking and use. We provided assessment ideas that move past a dichotomy between "scholarly" and "popular" sources and promote the guided use of the popular information sources (including those found via social media) that students encounter and use in their everyday lives.

The workshop generated great discussions about disciplinary assumptions, values, and expectations for information use, and prompted participants to think about how, where, and when information and digital literacies should be a part of a student's university experience. Many participants concluded that this is a larger conversation that needs to take place around campus, something that we intend to facilitate in the future through curriculum planning and educational development initiatives.

\section{Forming beneficial partnerships}

The benefits of forming partnerships between educational developers in academic teaching centers and librarians are significant. Our collaborative faculty workshop provides a contemporary example of how librarians can address the challenges of sustainability by meaningfully scaling up IL instruction and filling in gaps in traditional IL instruction programs. There is value in considering the learning needs of faculty when it comes to opening up conversations around integrating digital and information literacies, in planning for sustainable coverage of IL and DL, and in considering the potential impacts of an educational development approach to IL support for faculty and their students.

This type of partnership also provides an effective means of engaging faculty with IL and DL concepts. These workshops allowed us to frame these concepts in the context of a particular phenomenon-information disorder-that was relevant, timely, and applicable in various disciplinary contexts. We recently updated our face-to-face session to an online format including current issues surrounding fake news and the coronavirus pandemic, piloting it with an undergraduate audience in spring 2020, and we plan to facilitate an updated online workshop with this focus in order to meet faculty needs in fall 2020 .

\section{Conclusion}

This partnership between the Library and the Academic Development Centre provided an opportunity to reach interested faculty from a wide variety of departments and disciplines. Our approach enabled us to facilitate valuable cross-campus conversations with faculty about incorporating information and digital literacies across the curriculum-and, more importantly, in their own teaching.

By intentionally using an educational development lens, we resisted tendencies toward isolated "one and done" training techniques. Viewing our workshop as a simple but meaningful step toward addressing the larger problem of fake news and information disorder, we communicated the value of lifelong learning by sharing our own process of continuous growth in the face of these complex, evolving issues. We also encouraged others to keep building their knowledge and skills through ongoing professional development and reflective practice, making the avenues for future growth opportunities through our Library and Learning Centre transparent.

The need for greater faculty involvement in building digital literacy is clear. If information and digital literacy development is everyone's job, and if we do want to move beyond the one-shot student instruction model, then there is an opportunity for librarians to make use of their expertise and experience in new, collaborative relationships. In our experience, powerful partnerships between librarians and educational developers are one way to ignite wider curricular change and catalyze individual teaching improvement.

\section{Notes}

1. Alison J. Head, Erica DeFrain, Barbara 
Fister, and Margy MacMillan, "Across the Great Divide: How Today's College Students Engage with News," First Monday, 24, no. 8 (2019): 1-18, https://files.eric.ed.gov/fulltext/ ED597133.pdf.

2. Alison J. Head, Barbara Fister, and Margy MacMillan, Information Literacy in the Age of Algorithms: Student Experiences with News and Information, and the Need for Change, 2020, https://www.projectinfolit. org/uploads/2/7/5/4/27541717/algoreport. pdf.

3. Cheryl Amundsen and Mary Wilson, "Are We Asking the Right Questions? A Conceptual Review of the Educational Development Literature in Higher Education," Review of Educational Research, 82, no. 1 (2012): 90-126, https://doi. org/10.3102/0034654312438409.

4. Peter Felten, Alan Kalish, Allison Pingree, and Kathryn M. Plank, "Toward a Scholarship of Teaching and Learning in Educational Development," To Improve the Academy, 25, no. 1 (2007): 93, https://doi. org/10.1002/j.2334-4822.2007.tb00476.x.
5. Sharon B. Mader and Craig Gibson, Learning in Partnership, National Institute for Learning Outcomes Assessment, 2019, https://www.learningoutcomesassessment. org/wp-content/uploads/2019/10/ViewpointMaderGibson.pdf.

6. Sam Wineburg and Sarah McGrew, Lateral Reading: Reading Less and Learning More When Evaluating Digital Information, 2017, http://dx.doi.org/10.2139/ssrn.3048994.

7. NewsWise, "Online Verification Skills," YouTube video, June 29, 2018, https://www. youtube.com/playlist?list=PLsSbsdukQ8VYy8 8IiSJhz4NyBxxtLzsNr.

8. Head, Fister, and MacMillan, Information Literacy in the Age of Algorithms.

9. Erika E. Smith, Renate Kahlke, and Terry Judd, "From Digital Natives to Digital Literacy: Anchoring Digital Practices Through Learning Design," Proceedings of the Australasian Society for Computers in Tertiary Education, 510-515, http://2018conference. ascilite.org/.

10. Head, Fister, and MacMillan, Information Literacy in the Age of Algorithms. $\neq 2$

\section{Statement of ownership and management}

College E Research Libraries News is published 11 times a year (monthly, combining July/August) by the American Library Association, 225 N. Michigan Ave., Suite 1300, Chicago, IL 60601. American Library Association, owner; David Free, editor. Second-class postage paid at Chicago, Illinois. Printed in the U.S.A. As a nonprofit organization authorized to mail at special rates (DMM Section 423.12), the purposes, function, and nonprofit status of this organization and the exempt status for federal income tax purposes, have not changed during the preceding 12 months.

Extent and nature of circulation. ("Average" figures denote the number of copies printed each issue during the preceding twelve months; "Actual" figures denote the number of copies of single issues published nearest to filing date.) Total number of copies (net press run): Average, 10,481; Actual, 9,694. Total paid/ requested subscriptions: Average, 9,842; Actual, 9,049. Sales through dealers and carriers, street vendors, counter sales, and other non-USPS paid distribution: not applicable. Other classes mailed through the USPS: not applicable. Total paid and/or requested circulation: Average, 9,842 Actual, 9,049. Free distribution by mail: Average, 119; Actual, 115. Free distribution outside the mail: Average, 0; Actual, 0. Total free distribution: Average, 119; Actual, 115. Total distribution: Average, 9,961; Actual, 9,164. Copies not distributed: Office use, leftover, spoiled: Average, 520; Actual, 530. Total (sum of previous entries): Average, 10,481; Actual, 9,694. Percent paid and/or requested circulation: Average, 98.8\%; Actual, 98.9\%.

Statement of ownership, management, and circulation (PS Form 3526, July 2014) for 2020 filed with the United States Postal Service, Postmaster in Chicago, Illinois, August 24, 2020. 